\title{
BMJ Open Does chronic high-intensity endurance training have an effect on cardiovascular markers of active populations and athletes? Systematic review and meta- analysis
}

\author{
Gashaw Tesema (1D , ${ }^{1,2}$ Mala George, ${ }^{3}$ Abera Hadgu, ${ }^{4}$ Esayas Haregot, ${ }^{5}$ \\ Soumitra Mondal, ${ }^{6}$ D Mathivana ${ }^{6}$
}

To cite: Tesema G, George M, Hadgu $A$, et al. Does chronic high-intensity endurance training have an effect on cardiovascular markers of active populations and athletes? Systematic review and meta-analysis. BMJ Open 2019;9:e032832. doi:10.1136/ bmjopen-2019-032832

\section{- Prepublication history for} this paper is available online. To view these files, please visit the journal online (http://dx.doi. org/10.1136/bmjopen-2019032832).

Received 10 July 2019 Revised 24 September 2019 Accepted 30 September 2019

Check for updates

(c) Author(s) (or their employer(s)) 2019. Re-use permitted under CC BY-NC. No commercial re-use. See rights and permissions. Published by BMJ.

For numbered affiliations see end of article.

Correspondence to Dr Gashaw Tesema; gashtesema@gmail.com

\section{ABSTRACT}

Objective The objective of this study was to ascertain the effects of high-intensity chronic endurance training on cardiovascular markers of active populations and athletes. Methods This review was conducted in accordance with the guidelines of the Preferred Reporting Items for Systematic Reviews and Meta-Analyses. We used databases of PubMed, Science Direct, SPORTDiscus, Google Scholar and grey literatures with Mesh and free-text search as well as manual searches to identify relevant studies from June 2017 to September 2019. Weighted standardised mean differences and effect size of the intervention group versus the control group were calculated using a random effect model with $95 \% \mathrm{Cl}$.

Result There was significant improvement in high-density lipoprotein with weighted standardised mean difference and effect size $=-1.06(-1.83$ to -0.30$), p=0.006$. We have also observed a significant reduction in lowdensity lipoprotein and total cholesterol with weighted standardised mean difference and effect size $=-0.97$ $(-1.58$ to -0.36$), p=0.002$, and $=-0.78(-1.34$ to $-0.22), p=0.007$, respectively. There was a significant reduction in interleukin 6 (IL-6) using a fixed effect model with weighted standardised mean difference and effect size $=-0.87(-1.33$ to -0.40$), p=0.0003$ and $C$ reactive protein (CRP) with weighted standardised mean differences and effect size $=-0.41(-0.73$ to -0.09$)$, $\mathrm{p}=0.01$.

Conclusion Chronic high-intensity endurance training improves healthy lipid profiles (increase high-density lipoprotein, decreased low-density lipoprotein and total cholesterol). And decreased inflammatory markers (IL6 and CRP) independent of age and sex and cannot be associated with an increased risk of developing cardiovascular disease.

PROSPERO registration number CRD 42017081369.

\section{INTRODUCTION}

Regular endurance exercise is part of a healthy lifestyle associated with reduced cardiovascular disease (CVD) risk. ${ }^{1}$ Most studies observing CVD showed a gradual
Strengths and limitations of this study

- We used a systematic and comprehensive search strategy which resulted in an inclusive list of studies.

- We applied the Cochrane Risk of Bias Tool to assess the risk of bias from individual studies.

- We conduct the sensitivity analysis to test whether the conclusions are robust.

- We did not conduct subgroup analysis across age groups.

- The literature search was limited to articles published in English only because the authors did not have the resources to translate articles written in other languages.

decrease in CVD risk with progressively more exertion of the intensity. Even doses as low as 15 min of physical activity per day seem to reduce CVD risk and all causes of mortality. ${ }^{2}$ Higher intensity endurance training has also been reported with further reduced mortality risks, with the most active individuals demonstrating the best overall life expectancy. ${ }^{2}{ }^{3}$ However, recent evidence suggests that such intense exercise may actually increase CVD risk and not associated with better survival. ${ }^{45}$ Pheidippides was the first marathon runner exposed to sudden death in his 40 years old age during the Greco-Persian War in 490 BC. He collapsed after he runs 150 miles during the first 2 days and 26 miles during the third day from a battlefield near Marathon to Athens to deliver news of Greek victory. ${ }^{67}$ Now after 2500 years with the rise in popularity of endurance sports, athletes are exposed to adverse cardiac structural remodelling, and predispose to acute and chronic CVD problems. ${ }^{8}$ The rate of sudden cardiac death (SCD) among marathoners is approximately 1 per $100000-200000$ participants $^{9}$ 
and doubled in triathlon competitors. ${ }^{10}$ On the other hand, the mortality rate has increased as the number of participants increased. These deaths are caused by unsuspected CVDs. ${ }^{11}$ High-intensity exercise might have harmful effects on cardiac health by potentially generating myocardial fibrosis ${ }^{12}$ and exacerbated to arrhythmias $^{13}$ and SCD. The hypothesis for such a pathological adaptation is emerging and is based largely on medical evidence.

CVDs, such as atrial fibrillation ${ }^{14}$ and coronary artery calcification in apparently healthy male athletes above 55 years old,${ }^{15}$ have been reported in response to high-intensity endurance exercise and marathon running. Furthermore, chronic excessive endurance exercise may cause adverse physiological and morphological cardiac adaptations, particularly in the continuously growing middleaged amateur runners. ${ }^{16}$ Previous animal studies have also found that acute adverse cardiac effects have been observed in endurance exercise. ${ }^{17}$ Besides, a study of runners, those run less, up to 20 miles per week received a mortality benefit while those that run more than 20 miles per week did not gain significant additional health benefits. ${ }^{18}$ It would appear that a U-shaped relationship between exercise intensity and risk form training, where moderate-to-high intensity gained benefit, but inactivity and more extreme intensity may not always be beneficial. ${ }^{19}$

The prescription of endurance training is usually based on different levels of exercise intensity zones. ${ }^{20}$ However, the intensity level and duration of physical activity required to alter cardiovascular function and to reduce CVD risks are not yet defined. Training performed below a certain threshold intensity will have no hormonal response unless with a certain long duration. ${ }^{21}$ Training intensity and duration are crucial in causing hormonal changes as well as to trigger acute and chronic adaptation or to avoid overload..$^{22}$ However, much remains uncertain regarding the effects of chronic high-intensity endurance training on CVD biomarkers for targeted interventions and clinical evaluations. ${ }^{23}{ }^{24}$ Moreover, different studies revealed various results in response to chronic high-intensity endurance training. Accordingly, we aimed to perform a meta-analysis in order to provide a statistical summary of comparable studies as a means to consolidate a quantitative review of the effects of chronic high-intensity endurance training on cardiovascular markers. Therefore, the aim of this systematic review and meta-analysis was to assess the effects of chronic high-intensity endurance training on cardiovascular markers of active individuals and athletes', that is, inflammatory and lipoprotein markers. Thus, we hypothesised that chronic high-intensity endurance training might have no adverse effect on cardiovascular markers of active individuals and athletes.

\section{METHODS}

\section{Search strategy}

A literature search was conducted from June 2017 to September 2019. The following databases were searched:

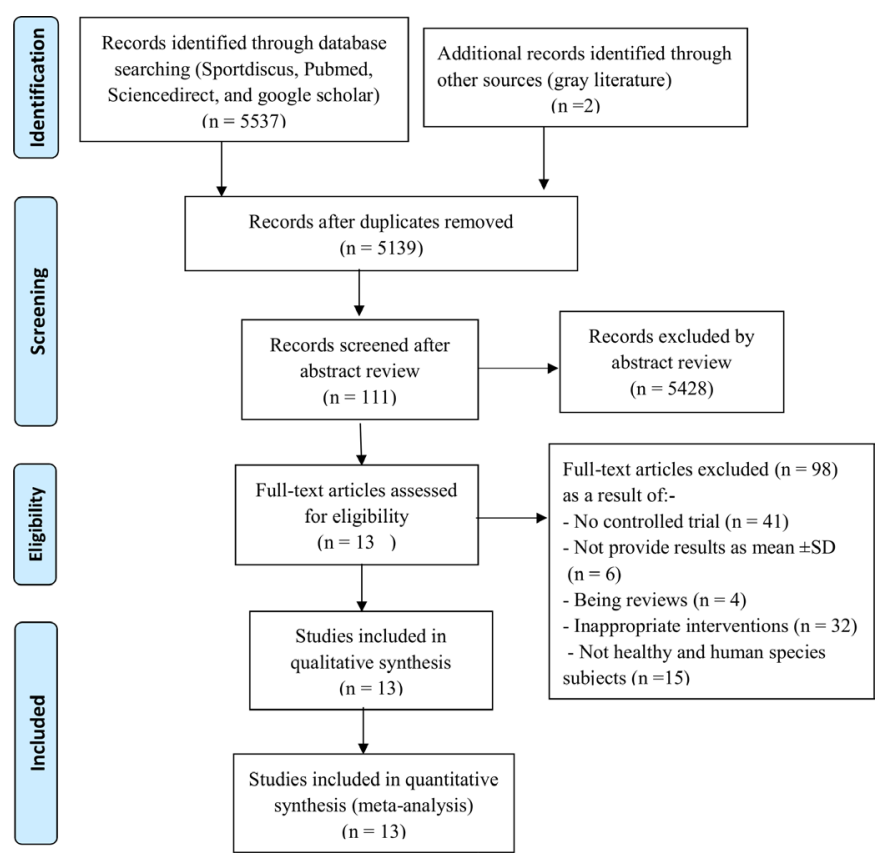

Figure 1 Preferred Reporting Items for Systematic Reviews and Meta-Analyses flow diagram of the study identification and selection process.

PubMed, Science Direct, SPORTDiscus, Google Scholar with Mesh and free-text search and grey literatures with manual search. Abstracts and citations from scientific conferences were excluded. This review was conducted in accordance with the guidelines of the Preferred Reporting Items for Systematic Reviews and Meta-Analyses (PRISMA). ${ }^{25} 26$

The three independent authors reviewed the studies at every stage and duplicates are managed together according to PRISMA flow diagram figure 1. Then decided whether inclusion is appropriate. Any disagreements between the three investigators were resolved by consensus to determine the inclusion of the study.

\section{Eligibility criteria}

Studies were eligible for inclusion in this review if: (1) the study included only healthy subjects; (2) studies observed high-intensity training above $70 \%$ HR max or above $70 \% \mathrm{VO}_{2}$ max training protocol; (3) studies seen endurance training done more than 7 weeks; (4) the study compares the outcomes of intervention group with the control group; (5) cardiovascular markers such as lipid and inflammatory markers were measured; (6) the study observed controlled trials; (7) the articles are published in English language from 1997 to September 2019. Citations out of the above criteria were excluded.

\section{Data extraction}

The following data were extracted: the characteristics of the participants in the control and intervention group, that is, sample size, age in mean and SD, the methodology used for endurance training (ie, type of training, intensity and duration), outcomes of cardiovascular markers measured at the end of the intervention like 
lipid/lipoprotein markers (ie, total cholesterol (TC), high-density lipoprotein (HDLc), low-density lipoprotein (LDLc)). Inflammatory markers (ie, interleukin 6 (IL-6), and $\mathrm{C}$ reactive protein $(\mathrm{CRP}))$.

\section{Data analysis}

We estimated outcomes using meta-analysis with random effects and pooled standardised mean difference of the changes of scores for TC, HDLc, LDLc and CRP in addition, fixed effect model for IL- 6 using $95 \%$ CI. We estimated a pooled standardised mean difference of the final values to avoid effect variation for outcomes that were measured and reported with different scales. We visually inspected funnel plots of the standardised mean difference versus SE and performed Egger's regression asymmetry test to assess bias due to small study effects. ${ }^{27}$ Except HDL, there was no indication of smallstudy effects available from the funnel plots or Egger's test for the rest four outcomes. Statistical heterogeneity between studies was tested using $Q$ statistics and quantified with $\mathrm{I}^{2}$ statistics. ${ }^{28}$ We have also seen the summary effect estimates of each outcome. We did not perform subgroup analysis since our objective is not to observe to which group endurance training has an effect. All the analysis has been done by using review manager software (RevMan V.5.3).

\section{Risk of bias in individual studies}

We used the Cochrane Risk of Bias Tool to assess the risk of bias in individual studies. ${ }^{29}$ The tool consists of the following seven domains: sequence generation, allocation concealment, blinding of participants and personnel, blinding of outcome assessment, incomplete outcome data, selective outcome reporting and 'other issues'. Each domain was considered for each of the included studies and the result of the overall risk of bias for each study was assessed and displayed using software RevMan V.5.3.

\section{Sensitivity analysis}

We did sensitivity analysis based on the impact of the statistical methods (mean difference or standardised mean difference) to check whether the conclusions would have been different if a different effect size measure had been used. We checked whether conclusions would have been the same if fixed-effect vs random-effect methods had been used. In addition, we did leave-one-out method to check whether the conclusions reached might differ substantially if a single study or a few studies were omitted..$^{30}$

\section{Patient and public involvement}

There were no patients' involvement in the development of the research question, and outcome measures, the design of this study, or the recruitment to and conduct of the study. The results will not be disseminated to study participants.
RESULT

\section{Study selection}

In the search strategy, we identified 5539 articles through online databases and grey literature. After removal of duplicates, 5139 citations were identified and after title and abstract screening 111 articles were included and 5428 were excluded. Out of 111 articles, 35 articles were included and 76 were excluded for full-text review. Out of this, 13 articles were selected for qualitative and quantitative synthesis (meta-analysis). The rest excluded as a result of no controlled trial, not provide results as mean $\pm \mathrm{SD}$, being reviews, inappropriate interventions, not healthy and human species subjects (figure 1).

\section{Study characteristics}

A total of 876 participants in the 13 studies were included, of which 433 experimental and 443 were in the control groups. Studies were published between 1997 and 2017 with English language. Of these, four were conducted in USA, ${ }^{31-34}$ two were conducted in Australia, ${ }^{35} 36$ one in Germany, ${ }^{37}$ one in Scotland, ${ }^{38}$ one in Poland, ${ }^{39}$ one in Estonia, ${ }^{40}$ two in Iran ${ }^{4142}$ and one in India. ${ }^{43}$ Three studies recruited only women ${ }^{31} 3242$ and two studies recruited both man and woman. ${ }^{34} 38$ The remaining eight studies recruited only male participants.

Age of participants of the study ranged from 16 to 89 years old. From these, three studies included participants with age of 16-22 years old, four studies included participants with age of 22-40 years old, ${ }^{33} 363742$ four studies included participants with age of 40-59 years old 31353940 and the rest two studies included participants with age of 60-89 years old. ${ }^{341}$

The participant training experience in included studies varies from sedentary to distance runners; from these, four studies included runners or athletes, three studies included active non-athlete participants, ${ }^{32} 3839$ one study included both athletes and non-athletes, ${ }^{43}$ one study included sedentary participants, ${ }^{33}$ two studies included overweight participant ${ }^{3642}$ and two studies included elderly and healthy ageing participants. ${ }^{34} 41$ Both participates more than 7-week endurance training.

The study protocol of each included study varied in intervention time from 7 weeks to 25 years and in endurance training type. From this, one study intervention was conducted with high-intensity interval training, ${ }^{35}$ one study conducted high-intensity intermittent endurance training, ${ }^{36}$ and three studies used high-intensity leisure time physical activity intervention. ${ }^{34} 39$ The remaining eight studies followed high-intensity continuous endurance training; see table 1 .

Even though some studies lack specificity, studies done above $70 \% \mathrm{HR}$ max or above $70 \% \mathrm{VO}_{2}$ max and studies used marathon training above 7 weeks included as high-intensity endurance exercise in this systematic review and meta-analysis.

Out of the 13 studies included in quantitative analysis, 10 reported CRP from these, 7 studies reported positive result for high-intensity endurance training adaptation 
Table 1 General characteristics of studies included in chronic effects of high-intensity endurance exercise

\begin{tabular}{|c|c|c|c|c|c|c|}
\hline Author and year & Subjects & Country & $\begin{array}{l}\text { Age, years and } \\
M \pm S D\end{array}$ & $\begin{array}{l}\text { Sample } \\
\text { size }\end{array}$ & Type of exercise & $\begin{array}{l}\text { Outcome } \\
\text { markers }\end{array}$ \\
\hline $\begin{array}{l}\text { Mattusch et al, } \\
2000^{37}\end{array}$ & Runners & Germany & $25-40$ & 22 & $\begin{array}{l}\text { 9-month college } \\
\text { marathon run preparation }\end{array}$ & CRP \\
\hline Taylor et al, 2014 31 & $\begin{array}{l}\text { Marathon } \\
\text { runners }\end{array}$ & $\begin{array}{l}\text { Boston, } \\
\text { USA }\end{array}$ & $46 \pm 13$ & 42 & $\begin{array}{l}\text { 3-month preparation for } \\
\text { Boston marathon }\end{array}$ & $\begin{array}{l}\text { CRP, HDL, } \\
\text { LDL, TC }\end{array}$ \\
\hline Allen et al, $2017^{35}$ & $\begin{array}{l}\text { Marathon } \\
\text { runners }\end{array}$ & Australia & $49.2 \pm 6.1$ & 34 & $\begin{array}{l}\text { 9-week high-intensity } \\
\text { interval training }\end{array}$ & CRP \\
\hline Pihl et al, $2003^{40}$ & $\begin{array}{l}\text { Endurance } \\
\text { athletes }\end{array}$ & Estonia & $48.0 \pm 6.1$ & 78 & $\begin{array}{l}23.1 \pm 6.3 \text { years } \\
\text { competitive endurance } \\
\text { sports }\end{array}$ & $\begin{array}{l}\text { HDL, LDL, TC, } \\
\text { CRP }\end{array}$ \\
\hline Vance et al, $2014^{33}$ & Sedentary men & Miami, USA & $22-37$ & 47 & $\begin{array}{l}\text { 17-week half-marathon } \\
\text { training }\end{array}$ & $\begin{array}{l}\text { HDL, LDL, } \\
\text { CRP }\end{array}$ \\
\hline $\begin{array}{l}\text { Kwaśniewska et al, } \\
2016^{39}\end{array}$ & $\begin{array}{l}\text { Leisure time } \\
\text { participants }\end{array}$ & Lodz, Poland & $\begin{array}{l}59.7 \\
\pm 9\end{array}$ & 62 & $\begin{array}{l}\text { 25-year high-intensity } \\
\text { leisure time physical } \\
\text { activity (PA) }\end{array}$ & $\begin{array}{l}\text { CRP, IL-6, LDL } \\
\text { HDL, TC }\end{array}$ \\
\hline Buchan et al, $2011^{38}$ & Students & Scotland, UK & $16.4 \pm 600.7$ & 57 & $\begin{array}{l}\text { 7-week brief intensive } \\
\text { and endurance exercise }\end{array}$ & $\begin{array}{l}\text { CRP, IL-6, } \\
\text { HDL, LDL, TC }\end{array}$ \\
\hline Dolati et al, $2017^{42}$ & $\begin{array}{l}\text { Overweight } \\
\text { women }\end{array}$ & Iran & $18-45$ & 24 & $\begin{array}{l}\text { 8-week total body } \\
\text { aerobic resistance } \\
\text { exercise programme }\end{array}$ & $\begin{array}{l}\text { LDL, HDL and } \\
\text { TC }\end{array}$ \\
\hline Nicklas et al, $2008^{34}$ & Elderly & USA & $70-89$ & 424 & $\begin{array}{l}\text { 12-month PA intervention } \\
\text { With successful ageing }\end{array}$ & CRP, IL-6 \\
\hline
\end{tabular}

CRP, C reactive protein; HDL, high-density lipoprotein; IL-6, interleukin 6; LDL, low-density lipoprotein; TC, total cholesterol.

and 3 studies reported that there was no significant change in CRP. Seven studies also reported HDL out of this: four studies reported significant change and three studies did not report significant increase. In addition, seven studies reported LDL from this: four studies not reported a positive result, but the remaining three studies reported a significant reduction. Six studies reported TC out of this: three studies reported positive results, but not the remaining three studies. Four studies reported IL-6 from this: only one study reported positive results and the remaining three studies did not report significant change.

\section{Lipid profile}

The findings of this systematic review and meta-analysis on lipoprotein markers (ie, HDL, LDL and TC) showed a significant difference in response to chronic high-intensity endurance training.

High-density lipoprotein

Seven studies with a total of 331 participants of which 159 participants in the intervention group and 172 participants in the control group were included in the analysis of HDL and we estimated a pooled standardised mean difference using a random-effect model. The intervention group showed statistically different result in HDL than the control group in response to chronic high-intensity endurance training with an effect estimate of the standardised mean difference in male ${ }^{-1}$ and $95 \% \mathrm{CI}=-1.06$ $(-1.83$ to -0.30$)$ and $\mathrm{p}=0.006$ (figure 2 ).

\section{Low-density lipoprotein}

Seven studies with a total of 331 participants of which 159 participants in the intervention group and 172 participants in the control group were included in the analysis of LDL and we estimated a pooled standardised mean differences using a random-effect model. The intervention group showed statistically different result in LDL than the control group in response to chronic high-intensity endurance training with an effect estimate of the standardised mean difference in $\mathrm{mmol}^{-1}$ and $95 \% \mathrm{CI}=-0.97$ $(-1.58$ to -0.36$)$ and $\mathrm{p}=0.002$ (figure 2$)$. 


\begin{tabular}{|c|c|c|c|c|c|c|c|c|}
\hline \multirow[b]{2}{*}{ Study or Subgroup } & \multicolumn{3}{|c|}{ Experimental } & \multicolumn{2}{|c|}{ Control } & \multicolumn{2}{|r|}{ Std. Ilean Difference } & \multirow{2}{*}{$\begin{array}{l}\text { Std. Mlean Difference } \\
\text { IV, Random, } 95 \% \mathrm{Cl}\end{array}$} \\
\hline & Mean & SD & Total & Mean & SD & Total Weight & IN, Random, $95 \% \mathrm{Cl}$ & \\
\hline Buchan ei al., 2011 & 1.83 & 1.41 & 17 & 2.2 & 1.46 & $2414.8 \%$ & $-0.25[-0.88,0.37]$ &  \\
\hline Dolati et al., $201 ?$ & 0.46 & 0.08 & 12 & 0.55 & 0.17 & $1213.8 \%$ & $-0.65[-1.48,0.17]$ & \\
\hline Hejudari el al., 2012 & 1.35 & 0.09 & 25 & 1.83 & 0.08 & $21 \quad 11.1 \%$ & $-5.51+6.82,-4.20]$ & $\hookleftarrow$ \\
\hline Kua ś niewska et al., 2018 & 1.41 & 0.45 & 15 & 1.81 & 0.39 & $2814.6 \%$ & $-0.95+1.62,-0.28]$ & $\rightarrow$ \\
\hline Pihl et al., 2003 & 1.34 & 0.27 & 29 & 1.38 & 0.3 & $2515.2 \%$ & $-0.14[-0.67,0.40]$ & \\
\hline Vance et al.. 2014 & 0.43 & 0.06 & 19 & 0.47 & 0.09 & $2214.8 \%$ & $-0.51[-1.13,0.12]$ & \\
\hline Zaleski et al., 2014 & 0.58 & 0.18 & 42 & 0.68 & 0.16 & $4215.6 \%$ & $-0.58+1.02,-0.14]$ & - \\
\hline Total $(95 \% \mathrm{Cl})$ & & & 159 & & & $172100.0 \%$ & $-1.06[-1.83,-0.30]$ & \\
\hline Heydari etal., 2012 & 2.35 & 0.18 & 25 & 2.81 & 0.16 & $21 \quad 13.3 \%$ & $-2.64[-3.45,-1.83]$ & I \\
\hline Dolati etal., 2017 & 0.98 & 0.19 & 12 & 1.32 & 0.15 & $1211.9 \%$ & $-1.92[-2.91,-0.92]$ & \\
\hline Vance etal., 2014 & 1.3 & 0.28 & 19 & 1.58 & 0.26 & $2214.5 \%$ & $-1.02[-1.68,-0.36]$ & \\
\hline Kwa ś niewska at al., 2016 & 1.41 & 0.45 & 15 & 1.81 & 0.39 & 2614.48 & $-0.95[-1.62,-0.28]$ & \\
\hline Zaleski et all., 2014 & 0.99 & 0.27 & 42 & 1.1 & 0.28 & $4216.0 \%$ & $-0.40[-0.83,0.04]$ & \\
\hline Buchan etal., 2011 & 1.45 & 0.58 & 17 & 1.73 & 1.21 & $24 \quad 14.7 \%$ & $-0.27[-0.90,0.35]$ & \\
\hline Pihl et al., 2003 & 3.56 & 0.81 & 29 & 3.6 & 1.23 & $25 \quad 15.3 \%$ & $-0.04[-0.57,0.50]$ & \\
\hline Total (95\% Cl) & & & 159 & & & $172100.0 \%$ & $-0.97[-1.58,-0.36]$ & \\
\hline Dolali et al., 2017 & 1.68 & 0.22 & 12 & 2.09 & $0.1 ?$ & $1212.7 \%$ & $-201[-3.03,-1.00]$ & \\
\hline Heydari et al.., 2012 & 3.97 & 0.24 & 25 & 4.36 & 0.18 & $2116.3 \%$ & $-1.78[-2.48,-1.09]$ & \\
\hline Pihl et al., 2003 & 5.04 & 1.02 & 29 & 5.77 & 1.15 & $2517.9 \%$ & $=0.66[-1.22, \cdot 0.11]$ & \\
\hline Buchan ol al.., 2011 & 3.55 & 1.81 & 17 & 3.96 & 1.45 & $2417.1 \%$ & $-0.25[-0.87,0.37]$ & \\
\hline Zaleskiet al., 2014 & 1.81 & 0.28 & 42 & 1.88 & 0.32 & $4219.2 \%$ & $-0.23[-0.66,0.20]$ & \\
\hline Kua ś niewska et âl., 2016 & 5.48 & 0.87 & 15 & 5.65 & 1.08 & $2616.9 \%$ & $=0.17[-0.80,0.47]$ & \\
\hline Total $(95 \mathrm{YC})$ & & & 140 & & & $150100.0 \%$ & $-0.78[-1.34,-0.22]$ & \\
\hline
\end{tabular}

Figure 2 Forest plot for high-density lipoprotein, low-density lipoprotein and total cholesterol.

Total cholesterol

Six studies ${ }^{31} 3638-4042$ with a total of 290 participants of which 140 participants in the intervention group and 150 participants in the control group were included in the analysis of TC and we estimated a pooled standardised mean difference using a random-effect model. The intervention group showed decrease in TC with statistically significant results than the control group in response to chronic high-intensity endurance training with an effect estimate of the standardised mean difference in $\mathrm{mmol}^{-1}$ and $95 \% \mathrm{CI}=-0.78(-1.34$ to -0.22$)$ and $\mathrm{p}=0.007$ (figure 2).

\section{Inflammatory markers}

In this meta-analysis in addition to lipoprotein markers, we observed inflammatory marker, that is, CRP and IL-6 and found significantly decreased results in response to chronic high-intensity endurance training.
Interleukin 6

Four studies ${ }^{34} 383943$ with a total of 526 participants of which 255 participants in the intervention group and 271 participants in the control group were included in the analysis of IL-6 and we estimated a pooled mean difference using a fixed-effect model. The rationale for using a fixed-effect model to this outcome is since the number of studies is very small, the estimate of the between-studies variance $\left(\tau^{2}\right)$ will have poor precision. In this case, we may choose among several options, each of them problematic. Random-effect model is still the appropriate model, but we lack the information needed to apply it correctly. The other option is to report the separate effects and not report a summary effect, but the problem is that some readers will revert to vote counting and possibly reach an erroneous conclusion. Another option is to perform a fixed-effect analysis. This approach would yield a descriptive analysis of the included studies, but would not allow 


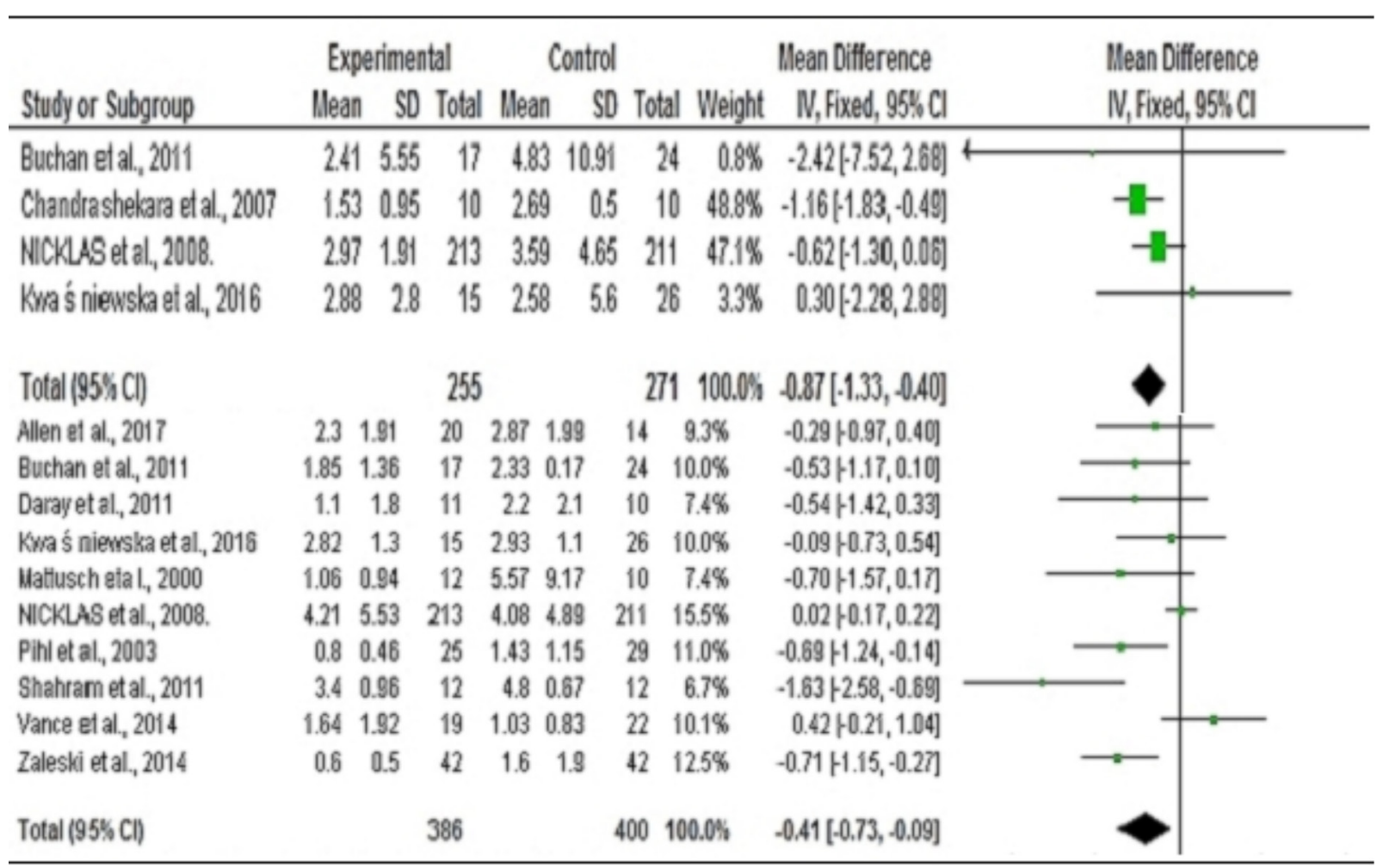

us to make inferences about a wider population. A third option is to take a Bayesian approach where the estimate of $\left(\tau^{2}\right)$ is based on data from outside of the current set of studies, but the problem is that we have to be expertise in Bayesian meta-analysis and some researchers have a philosophical objection to this approach. ${ }^{44}$ For this reason, we choose to use a fixed-effect model. As a result, intervention group showed statistically significant result in IL-6 than the control group in response to chronic high-intensity endurance training with effect estimate of mean difference in $\mathrm{pg} / \mathrm{mL}$ and $95 \% \mathrm{CI}=-0.87(-1.33$ to -0.40 ) and $\mathrm{p}=0.0003$ (figure 3 ).

\section{$C$ reactive protein}

Ten studies ${ }^{313-41}$ with a total of 786 participants of which 386 participants in the intervention group and 400 participants in the control group were included in the analysis of CRP and we estimated a pooled standardised mean difference using the random-effect model. The intervention group showed a significant decrease in CRP than the control group in response to chronic high-intensity endurance training with an effect estimate of the standardised mean difference in $\mathrm{mg} / \mathrm{L}$ and $95 \% \mathrm{CI}=-0.41$ $(-0.73$ to -0.09$)$ and $\mathrm{p}=0.01$ (figure 3$)$.

\section{Risk of bias}

We assessed the risk of bias for each study, according to the seven domains in the Cochrane Risk of Bias Tool and indicated in figure 4 . Challenges we face to assess risk of bias were incomplete reporting by authors where reporting detail made assessment possible. Most bias in the included studies was performance bias or lack of blinding of participants and personnel, which is difficult to manage in an exercise intervention study whereby exercise must be supervised. Two of the included studies have allocation concealment bias, ${ }^{40} 43$ one study had selection bias or random sequence generation ${ }^{38}$ and two studies have blinding of outcome assessment or detection bias $^{31} 32$ which creates difficulties in the outcome assessment (figure 4).

\section{DISCUSSION}

The purpose of this meta-analysis was to provide quantitative statistical summary of comparable studies to observe the effects of chronic high-intensity endurance training on cardiovascular markers in athletes and active populations. The main findings of this meta-analysis were lipoprotein markers (ie, HDL, LDL and TC) and inflammatory marker (ie, CRP, IL-6) which showed significantly different results in response to chronic high-intensity endurance training.

Various studies reported that exercise increases the levels of HDL through its lipoprotein expression which were analogous to the results of our meta-analysis. ${ }^{45}$ Consistently with the current meta-analysis, studies reported that there was significant increase in HDL and decrease in LDL and TC in response to endurance training. ${ }^{46}$ In line with this, our meta-analysis suggested that regular endurance exercise is particularly helpful to improve the lipid lipoprotein profile of men with low HDL cholesterol. ${ }^{47}$ We have also observed significant reduction of LDL and TC as a result of chronic high-intensity 


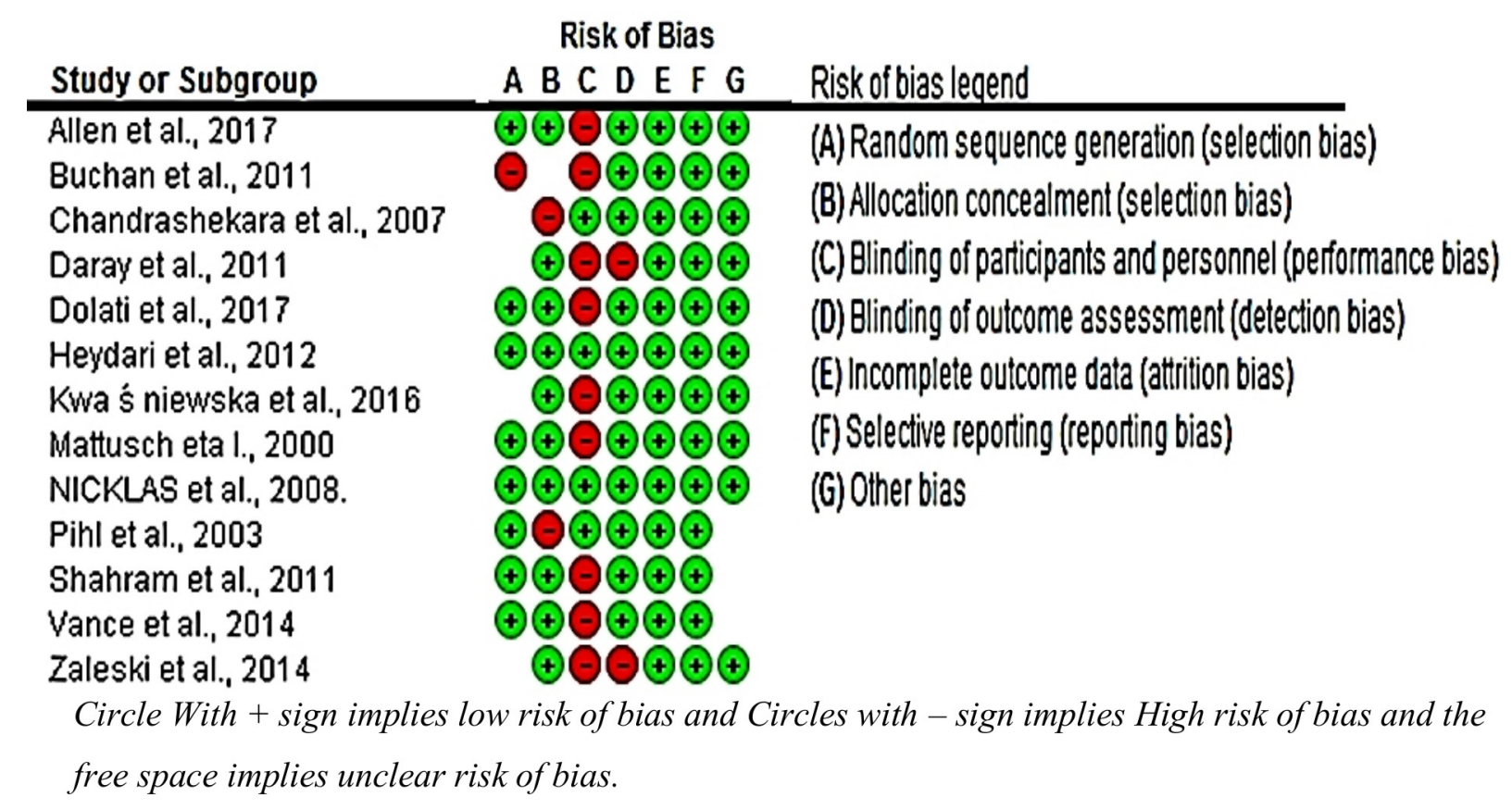

Figure 4 Cochrane risk of bias assessment for individual studies.

endurance training. Similarly with our result, a meta-analysis that analysed 31 trials reported an overall decrease in LDLc, TC and increase in HDLc as a result of endurance training. ${ }^{46}$ Consistently with our study, a meta-analysis by Goldhammer et $a t^{8}$ of 66 controlled trials reported an overall decrease in LDL, TC and with an increase in HDLc.

This meta-analysis revealed that IL-6 showed significantly different results of the experimental group than the controlled one. In line with our result, endurance training in patients with coronary artery disease is an effective means in reduction of IL-6 possibly improving coronary risk profile ${ }^{49}$ and it has anti-inflammatory properties and could have acted as an inhibitor of the inflammatory response to exercise. ${ }^{50}$ Similarly with our meta-analysis result, ${ }^{51}$ after 8 weeks and ${ }^{52}$ after 12 -week endurance training reported that there were decreases in IL-6. This change in IL-6 serum concentrations in response to long-term exercise training programme may vary from individual to individual due to genetic variations in the IL-6 gene independent of age and gender. ${ }^{53}$

In this meta-analysis, we found a significantly different result in CRP. In agreement with our result, studies reported that there are decreased CRP levels as a result of an adaptation to intense physical exercise by increasing levels of anti-inflammatory cytokines. ${ }^{50}$ Similarly, studies reported that endurance training is an effective means in inducing reduction in CRP and reducing coronary risk profile. ${ }^{491}$ Another studies reported that cytokines (IL-6 and CRP) were independently and inversely associated with a direct measure of cardiorespiratory fitness or $\mathrm{VO}_{2}$ $\max ^{54}$ indicating that when endurance exercise adapted and cardiorespiratory fitness improved, there will be decreased production of cytokines. Consistently with our result, a study on $\mathrm{CRP}^{55}$ reported that chronic endurance training reduces resting CRP levels by decreasing cytokine production in adipose tissue, skeletal muscles, endothelial and blood mononuclear cells and by improving endothelial function insulin sensitivity as well as antioxidant effect.

Generally, it is well known that in the majority of endurance athletes' lifelong habit of training and its adaptation will improve cardiovascular morbidity and mortality. ${ }^{56}$ Despite the fact that exercise at high relative intensity seems to induce larger beneficial adaptation in the cardiovascular system, it is unknown whether this type of training is safe for predisposed athletes. ${ }^{57}$ Consistently with our result, the prospective study from a study of US male physicians suggest that habitual vigorous exercise diminishes the risk of sudden death during vigorous exertion. ${ }^{58}$ The absolute magnitude of the increase in risk associated with vigorous exertion is extremely small, and the overall risk of sudden death was not increased in association with increasing frequency of vigorous exercise. ${ }^{58}$ Even sometimes, high-intensity endurance training is safe and highly relevant in patients with $\mathrm{CVD}^{59}$ if there is close monitoring during the training.

\section{CONCLUSION}

Generally, the results of the present meta-analysis provide evidence that chronic high-intensity endurance exercise improves healthy lipid profiles (increase HDL, LDL and TC) and decreased inflammatory markers (IL-6 as well as CRP) and it may not be associated with an increased risk of developing CVD. Further investigations should be done on the long-term effects of extremely high-intensity endurance training and genetic predisposition of individuals for cardiovascular problems exacerbated by exercise training based on age and sex differences. 


\section{Author affiliations}

${ }^{1}$ Department of Sport Science, College of Natural and Computetional sciences, Mizan-Tepi University, Tepi, Ethiopia

${ }^{2}$ Department of Sport Science, College of Natural and Computational Sciences, Mekelle University, Mekelle, Ethiopia

${ }^{3}$ Department of Biochemistry, College of Health Sciences, Mekelle University, Mekelle, Ethiopia

${ }^{4}$ Department of Pharmacology, College of Health Sciences, Mekelle University, Mekelle, Ethiopia

${ }^{5}$ Tigray Health Reaserch Institute, Mekelle, Ethiopia

${ }^{6}$ Department of Sport Science, College of Natural and Computational Sciences, Mekelle University, Mekelle, Ethiopia

Contributors All authors were involved in the design and concept of the study. MG involved in the consulting of the design and method of the study as well as in writing the manuscript. SM was involved in consulting the data gathering time and tools. DM was involved in designing theoretical framework of the study and GT involved from the conception to experiment and writing the manuscript. AH was involved in the systematic literature search and data extraction. EH was involved in statistical analysis.

Funding The authors have not declared a specific grant for this research from any funding agency in the public, commercial or not-for-profit sectors.

Competing interests None declared.

Patient consent for publication Not required.

Provenance and peer review Not commissioned; externally peer reviewed.

Data availability statement All data relevant to the study are included in the article or uploaded as supplementary information.

Open access This is an open access article distributed in accordance with the Creative Commons Attribution Non Commercial (CC BY-NC 4.0) license, which permits others to distribute, remix, adapt, build upon this work non-commercially, and license their derivative works on different terms, provided the original work is properly cited, appropriate credit is given, any changes made indicated, and the use is non-commercial. See: http://creativecommons.org/licenses/by-nc/4.0/.

ORCID iD

Gashaw Tesema http://orcid.org/0000-0001-8962-2313

\section{REFERENCES}

1. Shiroma EJ, Lee I-M. Physical activity and cardiovascular health: lessons learned from epidemiological studies across age, gender, and race/ethnicity. Circulation 2010;122:743-52.

2. Wen CP, Wai JPM, Tsai MK, et al. Minimum amount of physical activity for reduced mortality and extended life expectancy: a prospective cohort study. The Lancet 2011;378:1244-53.

3. Marijon E, Tafflet M, Antero-Jacquemin J, et al. Mortality of French participants in the tour de France (1947-2012). Eur Heart $J$ 2013;34:3145-50.

4. Croft AM, Palmer JV. Exercise and life expectancy. Lancet 2012;379:800-1.

5. Lee Jet al. Running and all-cause mortality risk: is more better? Med Sci Sport Exerc 2012;44:990-4.

6. Ford J. Running. In: Physical education paper, 2003

7. Ali P, Beechey P. Spartathlon \& The Legend of Pheidippides Birtish Spartalon Team; 2017: 1-28.

8. O'Keefe JH, Vogel R, Lavie CJ, et al. Achieving hunter-gatherer fitness in the 21(st) century: back to the future. Am J Med 2010;123:1082-6.

9. Kim JH, Malhotra R, Chiampas G, et al. Cardiac arrest during longdistance running races. N Engl J Med 2012;366:130-40.

10. Harris KM, Henry JT, Rohman E, et al. Sudden death during the triathlon. JAMA 2010;303:1255-7.

11. Maron BJ, Thompson PD, Ackerman MJ, et al. Recommendations and considerations related to Preparticipation screening for cardiovascular abnormalities in competitive athletes: 2007 update. Circulation 2007;115:1643-55.

12. La Gerche A, Connelly KA, Mooney DJ, et al. Biochemical and functional abnormalities of left and right ventricular function after ultra-endurance exercise. Heart 2008;94:860-6.

13. Kawara T, Derksen R, de Groot JR, et al. Activation delay after premature stimulation in chronically diseased human myocardium relates to the architecture of interstitial fibrosis. Circulation 2001;104:3069-75

14. Mont L, Elosua R, Brugada J, et al. Endurance sport practice as a risk factor for atrial fibrillation and atrial flutter. Europace 2009;11:11-17.

15. Möhlenkamp S, Lehmann N, Breuckmann F, et al. Running: the risk of coronary events: Prevalence and prognostic relevance of coronary atherosclerosis in marathon runners. Eur Heart $J$ 2008;29:1903-10.

16. Predel H-G. Marathon run: cardiovascular adaptation and cardiovascular risk. Eur Heart J 2014;35:3091-8.

17. Praphatsorn P, Thong-Ngam D, Kulaputana O, et al. Effects of intense exercise on biochemical and histological changes in rat liver and pancreas. Asian Biomed 2010;4:619-25.

18. Lee Jet al. Running and all-cause mortality risk: is more better. Med Sci Sport Exerc 2012;44:990-4.

19. Merghani A, Malhotra A, Sharma S, et al. The U-shaped relationship between exercise and cardiac morbidity. Trends Cardiovasc Med 2016;26:232-40.

20. Meyer T, Lucía A, Earnest CP, et al. A conceptual framework for performance diagnosis and training prescription from submaximal gas exchange parameters--theory and application. Int J Sports Med 2005;26 Suppl 1:S38-48.

21. Viru A. Determinants and modulators of hormonal responses to exercise. Biol Sport 1996;13:169-87.

22. Viru A. Adaptation in sports training. Boca Raton, FL: CRC Press, 1995.

23. Lavie CJ, Church TS, Milani RV, et al. Impact of physical activity, cardiorespiratory fitness, and exercise training on markers of inflammation. J Cardiopulm Rehabil Prev 2011;31:137-45.

24. Kelley GA, Kelley KS. Effects of aerobic exercise on C-reactive protein, body composition, and maximum oxygen consumption in adults: a meta-analysis of randomized controlled trials. Metabolism 2006;55:1500-7.

25. Moher D, Liberati A, Tetzlaff J, et al. Preferred reporting items for systematic reviews and meta-analyses: the PRISMA statement. $J$ Clin Epidemiol 2009;62:1006-12.

26. Panic N, Leoncini E, de Belvis G, et al. Evaluation of the endorsement of the preferred reporting items for systematic reviews and meta-analysis (PRISMA) statement on the quality of published systematic review and meta-analyses. PLoS One 2013;8:e83138.

27. Egger M, Davey Smith G, Schneider M, et al. Bias in meta-analysis detected by a simple, graphical test. BMJ 1997;315:629-34.

28. Higgins JPT, Thompson SG. Quantifying heterogeneity in a metaanalysis. Stat Med 2002;21:1539-58.

29. Higgins JPT, Altman DG, Gotzsche PC, et al. The Cochrane collaboration's tool for assessing risk of bias in randomised trials. BMJ 2011;343.

30. Michael Borenstein LV, Hedges J. Introduction to meta-analysis. John Wiley \& Sons, Ltd, 2009: 368-9.

31. Taylor BA, Zaleski AL, Capizzi JA, et al. Influence of chronic exercise on carotid atherosclerosis in marathon runners. BMJ Open 2014:4:e004498.

32. Daray LA, Henagan TM, Zanovec M, et al. Endurance and resistance training lowers C-reactive protein in young, healthy females. Appl Physiol Nutr Metab 2011;36:660-70.

33. Vance DD, Chen GL, Stoutenberg M, et al. Cardiac performance, biomarkers and gene expression studies in previously sedentary men participating in half-marathon training. BMC Sports Sci Med Rehabil 2014;6:6.

34. Nicklas BJ, Hsu F-C, Brinkley TJ, et al. Exercise training and plasma C-reactive protein and interleukin-6 in elderly people. J Am Geriatr Soc 2008;56:2045-52.

35. Allen NG, Higham SM, Mendham AE, et al. The effect of highintensity aerobic interval training on markers of systemic inflammation in sedentary populations. Eur J Appl Physiol 2017;117:1249-56

36. Heydari M, Freund J, Boutcher $\mathrm{SH}$, et al. The effect of high-intensity intermittent exercise on body composition of overweight young males. J Obes 2012;2012:1-8

37. Mattusch F, Dufaux B, Heine $O$, et al. Reduction of the plasma concentration of $\mathrm{C}$-reactive protein following nine months of endurance training. Int J Sports Med 2000;21:21-4.

38. Buchan DS, Ollis S, Young JD, et al. The effects of time and intensity of exercise on novel and established markers of CVD in adolescent youth. Am J Hum Biol 2011;23:517-26.

39. Kwaśniewska M, Kostka T, Jegier A, et al. Regular physical activity and cardiovascular biomarkers in prevention of atherosclerosis in men: a 25-year prospective cohort study. BMC Cardiovasc Disord 2016;16:65

40. Pihl E, Zilmer K, Kullisaar T, et al. High-Sensitive C-reactive protein level and oxidative stress-related status in former athletes in 
relation to traditional cardiovascular risk factors. Atherosclerosis 2003:171:321-6.

41. Shahram S. Effects of endurance training on inflammatory markers predictor of cardiovascular disease in aging men. IPCBEE, 2011:5.

42. Dolati M, Ghazalian F, Abednatanzi $\mathrm{H}$, et al. The effect of a period of TRX training on lipid profile and body composition in overweight women. Int J Sport Sci 2017;7:151-8.

43. Gokhale R, Chandrashekara S, Vasanthakumar KC, et al. Cytokine response to strenuous exercise in athletes and non-athletes--an adaptive response. Cytokine 2007;40:123-7.

44. Michael Borenstein L. Introduction to meta-analysis. John Wiley \& Sons, Ltd, 2009

45. Plaisance EP, Grandjean PW, Mahurin AJ, et al. Independent and combined effects of aerobic exercise and pharmacological strategies on serum triglyceride concentrations: a qualitative review. Phys Sportsmed 2009;37:11-19.

46. Halbert JA, Silagy CA, Finucane P, et al. Exercise training and blood lipids in hyperlipidemic and normolipidemic adults: a meta-analysis of randomized, controlled trials. Eur J Clin Nutr 1999;53:514-22.

47. Couillard C, Després JP, Lamarche B, et al. Effects of endurance exercise training on plasma HDL cholesterol levels depend on levels of triglycerides: evidence from men of the health, risk factors, exercise training and genetics (HERITAGE) family study. Arterioscler Thromb Vasc Biol 2001;21:1226-32.

48. Tran ZV, Weltman A, Glass GV, et al. The effects of exercise on blood lipids and lipoproteins: a meta-analysis of studies. Med Sci Sports Exerc 1983;15:393-402.

49. Goldhammer E, Tanchilevitch A, Maor I, et al. Exercise training modulates cytokines activity in coronary heart disease patients. Int $J$ Cardiol 2005;100:93-9.

50. Petersen AMW, Pedersen BK. The anti-inflammatory effect of exercise. J Appl Physiol 2005;98:1154-62.
51. Sponder M, Campean I-A, Emich M, et al. Long-Term endurance training increases serum cathepsin S and decreases IL-6 and hsCRP levels. J Sports Sci 2017;35:2129-34.

52. Farinha JB, Steckling FM, Stefanello ST, et al. Response of oxidative stress and inflammatory biomarkers to a 12-week aerobic exercise training in women with metabolic syndrome. Sports Med Open $2015 ; 1$.

53. Oberbach A, Lehmann S, Kirsch K, et al. Long-Term exercise training decreases interleukin-6 (IL-6) serum levels in subjects with impaired glucose tolerance: effect of the $-174 \mathrm{G} / \mathrm{C}$ variant in IL-6 gene. Eur $J$ Endocrinol 2008;159:129-36.

54. Kullo IJ, Khaleghi M, Hensrud DD. Markers of inflammation are inversely associated with VO2 max in asymptomatic men. $J$ Appl Physiol 2007;102:1374-9.

55. Kasapis C, Thompson PD. The effects of physical activity on serum $C$-reactive protein and inflammatory markers: a systematic review. $J$ Am Coll Cardiol 2005;45:1563-9.

56. George K, Whyte GP, Green DJ, et al. The endurance athletes heart: acute stress and chronic adaptation. Br J Sports Med 2012;46 Supp 1:i29-36.

57. Wisløff U, Ellingsen Øyvind, Kemi OJ, et al. High-Intensity interval training to maximize cardiac benefits of exercise training? Exerc Sport Sci Rev 2009;37:139-46.

58. Albert CM, Mittleman MA, Chae CU, et al. Triggering of sudden death from cardiac causes by vigorous exertion. $N$ Engl J Med 2000;343:1355-61.

59. Kolmos M, Krawcyk RS, Kruuse C, et al. Effect of high-intensity training on endothelial function in patients with cardiovascular and cerebrovascular disease: a systematic review. SAGE Open Med 2016;4:2050312116682253. 